Japan, J. Med. Sci. Biol., 36, 75-83, 1983

\title{
CLOSTRIDIUM OEDEMATIENS ANTITOXIN: THE CORRELATION BETWEEN ANTI-LETHAL AND ANTI-EDEMATIZING ACTIVITIES
}

\author{
NANAE IZUMI, YoIchi TOKUMARU and Hisashi KONDO \\ Chiba Serum Institute, Konodai, Ichikawa-shi, Chiba 272
}

(Received November 29, 1982. Accepted January 13, 1983)

\begin{abstract}
SUMMARY: To re-evaluate the current potency tests of $C$. oedematiens antitoxin that titrates only the anti-lethal activity in mice, investigations were made on neutralization of the lethal, edematizing, and hemolytic activities with different preparations of the antitoxin and on their therapeutic effects. The anti-lethal and anti-edematizing potencies of antitoxins prepared by hyperimmunization with each of crude and purified antigens were the same when titrated with either crude or purified lethal toxin as test toxin. The two antitoxins protected mice equally against the lethal and edematizing activities of crude toxin. The antitoxin prepared against highly purified hemolytic toxin contained neither anti-lethal nor antiedematizing activity. We conclude that the lethal and edematizing activities of C. oedematiens are borne by the same molecule and that the therapeutic effect of the antitoxin may depend entirely on the anti-lethal (or anti-edematizing) activity. The method currently used for titrating $C$. oedematiens antitoxin, therefore, appears to be valid.
\end{abstract}

\section{INTRODUCTION}

Gas gangrene antitoxin used in Japan is a mixture of $C$. perfringens, $C$. septicum, and $C$. oedematiens antitoxins. The method currently used to titrate these antitoxins involves titration of the anti-lethal activity in mice with each of the three toxins as test toxin (Ministry of Health and Welfare, 1973).

Gas gangrene organisms produce, besides the lethal toxin, many other different toxins (Oakley, Warrack and Clarke, 1947; Oakley and Warrak, 1959). As $\alpha$-toxin (phospholipase C) of $C$. perfringens showing lethal activity plays the main role in the pathogenesis of gas gangrene (Evans, 1943, 1945; Ito, Kameyama and Murata, 1977), it seems justified that the potency of $C$. perfringens antitoxin is expressed in terms of the anti-lethal (anti- $\alpha$ toxin) potency. Wound infection with $C$. oedematiens is characterized by severe edema and high fatality (Oakley et al., 1947; Willis, 1969; Aikat and Dible, 1960; Glenny, Llewellyn-Jones and Mason, 1931). It is known that $C$. oedematiens toxin exhibits various activities; lethal, edematizing, necrotic, hemolytic (Macfarlene, 1950b), lecithinase (Macfarlene, 1950a; Taguchi and Ikezawa, 1975), permeability-enhancing (Elder and Miles, 1957), cytotoxic (Rutter and Collee, 1969; Ermakova et al., 1971), etc. Although it has not been clarified whether or not the lethal and edematizing 泉 七江・徳丸洋一・近藤 久 (千葉県立血清研究所 市川市国府台 2-6-1) 
activities are elicited by the same molecule, the potency of $C$. oedematiens antitoxin is expressed only in the anti-lethal activity in mice. It is not known whether the anti-lethal and anti-edematizing potencies are directly associated or whether these potencies are associated with the antibodies to any other activity. It appeared very important to clarify such relations in the potency test and in the therapeutic effect of $C$. oedematiens antioxin.

The studies on $C$. oedematiens toxin reported in the preceding paper (Izumi, Niiro and Kondo, 1983) indicated that the hemolytic and lecithinase activities are each separable from the lethal and edematizing activities, and that the lethal and edematizing activities may be borne by the same molecule.

The relation between lethal and edematizing activities of $C$. oedematiens toxin was investigated more in detail by neutralization of each activity with different preparations of the antitoxin and the method currently used to titrate C. oedematiens antitoxin was re-evaluated.

\section{Materials ANd Methods}

Toxins: Crude toxins (C-1 and C-2), culture filtrates of C. oedematiens type A strain 140 and the lethal toxin partially purified (P-1) by Sephadex G-100 gel filtration (Izumi et al., 1983) were used.

Antitoxins: The standard C. oedematiens antitoxin (Lot C) was given by National Institute of Health, Tokyo, and reconstituted to 20 International Units $(\mathrm{U}) / \mathrm{ml}$ in glycerinated saline.

The antitoxins examined were prepared by immunizing horses with each of toxoids prepared by treating with formalin of crude and purified toxins. The antitoxin prepared with crude antigen was named C-AT and that with purified antigen P-AT. The standard antitoxin was a C-AT type.

Titration of lethal and edematizing activities $\left(L D_{50}\right.$ and $\left.O E D_{50}\right): L_{50}$ and $\mathrm{OED}_{50}$ were determined by the method of Izumi et al. (1983).

Titration of antitoxins: The diluent used for titration of antitoxin was $0.2 \%$ gelatin- $0.0167 \mathrm{~m}$ phosphate buffered saline, $\mathrm{pH} 7.0$. To titrate anti-lethal, anti-edematizing and anti-hemolytic activities, $\mathrm{L}+/ 50, \mathrm{LE} / 50$ and $\mathrm{Lh} / 50$ levels were used, respectively. For example, $\mathrm{L}+/ 50$ dose of the toxin was defined as the amount of toxin which, when mixed with 0.02 units of antitoxin and injected intramuscularly into mice, kills within 2 days in $50 \%$ of the mice.

1) Anti-lethal and anti-edematizing potencies. The antitoxin was diluted 1.25-fold serially for 5-6 steps. Each dilution was mixed with an equal quantity of the test toxin. The mixture was kept standing for an hour at room temperature and a 0.2-ml portion was injected intramuscularly on the thigh of each mouse weighing about $18 \mathrm{~g}$. The same was performed with the standard antitoxin. The mice were observed for 2 days for death. The anti-lethal potency was calculated and expressed in relation to that of the standard antitoxin. The anti-edematizing potency was obtained by examining the injection site of the stripped skin of the mice having survived for 2 days. The fiducial limits 
for anti-lethal and anti-edematizing potencies were $82-122 \%$ at $95 \%$ level of probability, respectively.

2) Anti-hemolytic potency. The antitoxin was diluted twofold serially for 8-10 steps. A $0.025-\mathrm{ml}$ portion of each dilution was mixed with an equal quantity of the test toxin. The mixture was kept standing for $20 \mathrm{~min}$ at $33 \mathrm{C}$, then $0.025-\mathrm{ml}$ of a $0.1 \%$ L-cysteine- $2 \%$ horse erythrocyte suspension was added. They were kept standing for $2 \mathrm{hr}$ at $33 \mathrm{C}$ followed by overnight in a refrigerator. The same series was made with the standard antitoxin. Hemolysis was read and the potency was calculated in relation to that of the standard antitoxin.

Construction of the neutralization curve: The neutralization curve was constructed by the multiple level $\alpha$ procedure. The antitoxin was so diluted serially four steps that each would contain $0.2,0.063,0.02$, or $0.0063 \mathrm{U} /$ dose. Each level of antitoxin in a fixed volume was mixed with an equal volume of each toxin dilution graded at 1.4-fold. The mixtures were kept standing for an hour at room temperature and injected intramuscularly in $0.2-\mathrm{ml}$ doses into the thigh of each mouse weighing about $18 \mathrm{~g}$.

The mice were observed for 2 days and the toxin dose required to kill half of the mice was calculated for each level to construct a neutralization curve with lethality as an indicator. To construct a neutralization curve with edema formation as an indicator, the skin of the thigh was removed in 2 days and the amount of the toxin required to cause edema at the injection sites of half of the mice was calculated at each level. The neutralization curve was drawn by plotting the logarithm of the amount of the antitoxin in the ordinate and the logarithm of the amount of the toxin in the abscissa.

\section{RESUlts}

\section{Comparison of the Neutralization Curves of Antitoxins}

The toxins used were C-1 and P-1. The antitoxins used were from a horse hyperimmunized with the crude antigen (C-AT-1) and from another horse immunized with the purified antigen (P-AT-1).

In Fig. 1 are shown neutralization curves obtained with the anti-lethal activity of the antitoxin as an indicator. The curve marked with closed circles was obtained with C-1 and C-AT-1 and that marked with open circles was with C-1 and P-AT-1. The curves are identical to each other. The curve marked with closed triangles was obtained with P-1 and C-AT-1 and that marked with open triangles with P-1 and P-AT-1. They were also identical to each other. Furthermore the four curves run parallel from one to another. The common slope (b) of these curves was 1.07 .

In Fig. 2 are shown neutralization curves obtained with the anti-edematizing activity of the antitoxin as an indicator. The symbols were the same as those in Fig. 1. The neutralization curves of the antitoxins obtained against C-1 and P-1 toxins were identical to each other and the four curves run parallel from 


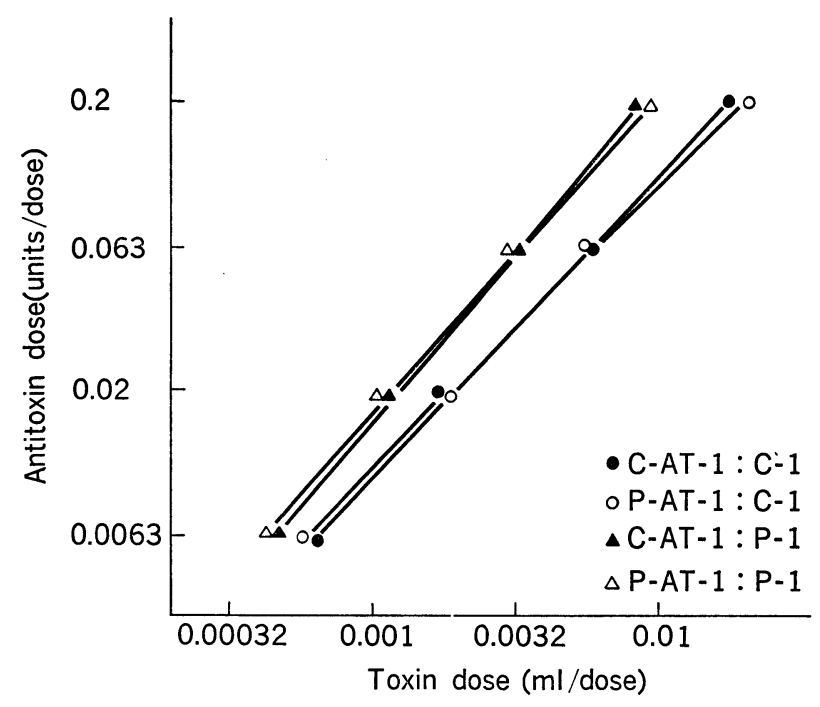

Fig. 1. Neutralization curves of the antitoxins obtained with the anti-lethal activity as an indicator.

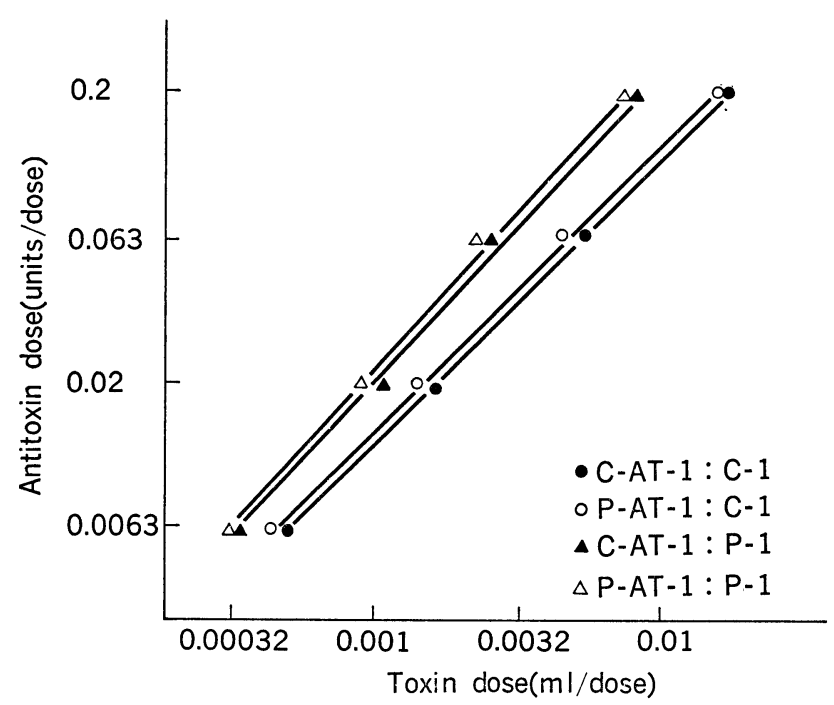

Fig. 2. Neutralization curves of the antitoxins obtained with the anti-edematizing activity as an indicator.

one to another with $\mathrm{b}$ of approximately 1.00. When the amount of antitoxin required for neutralization was expressed in units, the neutralization curves were identical to each other regardless of the antitoxin used. The different intercepts of the neutralization curves of C-1 and P-1 reflect the different combining powers of these toxins. 
The Correlation between the Anti-lethal and Anti-edematizing

Potencies of the Antitoxins

The antitoxins obtained by hyperimmunization of horses and guinea pigs with crude or purified antigen were titrated for the anti-lethal and antiedematizing potencies. Three toxin preparations, C-1, C-2 and P-1, were used as test toxins. The anti-lethal and anti-edematizing potencies were titrated at $\mathrm{L}+/ 50$ and $\mathrm{LE} / 50$ levels, respectively (Table I). The anti-edematizing potencies are shown in parentheses.

The same anti-lethal potencies were obtained with any antitoxin with either crude or purified toxin as test toxin. The same was true also with the anti-edematizing potency. The anti-lethal and anti-edematizing potencies of any antitoxin gave the same ratios.

TABLE I

Anti-lethal and anti-edematizing activities of various antitoxins

Test levels: $\mathrm{L}+/ 50$ and $\mathrm{LE} / 50$

\begin{tabular}{|c|c|c|c|c|}
\hline \multirow{2}{*}{ Antigen } & \multirow{2}{*}{ Animal } & \multicolumn{3}{|c|}{$\begin{array}{l}\text { Anti-lethal (anti-edematizing) activity } \\
\text { (U/ml) with test toxin }\end{array}$} \\
\hline & & $\mathrm{C}-1$ & $\mathrm{C}-2$ & P-1 \\
\hline \multirow{2}{*}{ Crude } & Horse & $280(320)^{*}$ & - & $320(320)$ \\
\hline & Guinea pig & $63(56)$ & $63(71)$ & 63 (63) \\
\hline \multirow{2}{*}{ Purified } & Horse & $560(560)$ & $560(710)$ & $630(560)$ \\
\hline & Horse & $450(450)$ & $400(450)$ & $400 \quad(400)$ \\
\hline
\end{tabular}

* Anti-edematizing activities are given in parentheses.

The Relation between the Anti-hemolytic and Anti-lethal

(and Anti-edematizing) Potencies of the Antitoxins

Crude (C), highly purified lethal (AA), and highly purified hemolytic toxins (DD) were transformed to toxoids and rabbits were immunized with each toxoid. Primary injections were given three times at 3-day intervals. From 2 weeks after the last injection, additional two or three booster injections were given every week. Antitoxins were titrated for anti-lethal, anti-edematizing and antihemolytic potencies (Table II).

The antitoxins of rabbits Nos. 1 and 2 immunized with crude antigen gave similar anti-lethal and anti-edematizing potencies and anti-hemolytic potency was also detectable. The antitoxins of rabbits Nos. 3 and 4 immunized with AA also gave similar anti-lethal and anti-edematizing potencies, but the antihemolytic potency was undetectable, being lower than $0.32 \mathrm{U} / \mathrm{ml}$. In the antitoxin of rabbit No. 6 immunized with DD, the anti-hemolytic potency increased as immunization advances from V to VII, but neither anti-lethal nor antiedematizing potency was detectable, being below $0.2 \mathrm{U} / \mathrm{ml}$. 
TABLE II

Anti-lethal and anti-edematizing activities of rabbit antitoxins against crude, purified lethal or hemolytic antigen

Test levels: $\mathrm{L}+/ 50, \mathrm{LE} / 50$ and $\mathrm{Lh} / 50$

\begin{tabular}{ccccc}
\hline Antigen & Antitoxin & $\begin{array}{c}\text { Anti-lethal } \\
\text { activity } \\
(\mathrm{U} / \mathrm{ml})^{1}\end{array}$ & $\begin{array}{c}\text { Anti-edematizing } \\
\text { activity } \\
(\mathrm{U} / \mathrm{ml})^{1}\end{array}$ & $\begin{array}{c}\text { Anti-hemolytic } \\
\text { activity } \\
(\mathrm{U} / \mathrm{ml})^{2}\end{array}$ \\
\hline \multirow{2}{*}{$\mathrm{C}^{3}$} & $\mathrm{R}-1$ & 11 & 8 & 10 \\
& $\mathrm{R}-2$ & 20 & 20 & 14 \\
\hline \multirow{2}{*}{$\mathrm{AA}^{4}$} & $\mathrm{R}-3$ & 6.5 & 5.6 & $<0.32$ \\
& $\mathrm{R}-4$ & 16 & 13 & $<0.32$ \\
\hline \multirow{2}{*}{$\mathrm{DD}^{5}$} & $\mathrm{R}-6-\mathrm{V}$ & $<0.2$ & $<0.2$ & 1.25 \\
& $\mathrm{R}-6-\mathrm{VI}$ & $<0.2$ & $<0.2$ & 5 \\
& $\mathrm{R}-6-\mathrm{VII}$ & $<0.2$ & $<0.2$ & 10 \\
\hline
\end{tabular}

1 Titers obtained by titration with purified lethal toxin (P-1) as test toxin.

2 Titers obtained by titration with purified hemolytic toxin as test toxin.

3 Crude antigen. 4 Highly purified lethal antigen. ${ }^{5}$ Highly purified hemolytic antigen.

\section{The Therapeutic Effects of Antitoxins}

The antitoxin obtained by hyperimmunization with crude antigen (C-AT-2) and that with purified antigen (P-AT-2) were compared with each other in the protective effects against both lethal and edematizing activities. The titers of C-AT-2 and P-AT-2 were $640 \mathrm{U} / \mathrm{ml}$ and $430 \mathrm{U} / \mathrm{ml}$ in anti-lethal activity and, $680 \mathrm{U} / \mathrm{ml}$ and $420 \mathrm{U} / \mathrm{ml}$ in anti-edematizing activity, respectively.

1) Comparison of antitoxins in protection of mice against lethal activity. Crude toxin (C-1) was so diluted that an injection dose would contain $5.6 \mathrm{LD}_{50}$ and it was injected intramuscularly into the thigh of each mouse weighing about $18 \mathrm{~g}$. In 1,2 or $3 \mathrm{hr}$, antitoxin, being serially diluted so that an injection dose would contain $0.001-1 \mathrm{U}$ (in anti-lethal potency), was injected intravenously. The mice were observed for two days for deaths (Table III).

The longer the period between the injections of toxin and anti-toxin, the larger the amount of antitoxin necessary to protect mice against the lethality. At different periods, antitoxins C-AT-2 and P-AT-2 were compared with each other for $\mathrm{ED}_{50}$. No significant difference was found between them. From the results of other experiments, $0.1 \mathrm{U}$ of either antitoxin neutralized in vitro about $560 \mathrm{LD}_{50}$ of $\mathrm{C}-1$.

2) Comparison of antitoxin in protection of mice against edema. Crude toxin (C-1) was so diluted that an injection dose would contain $5.6 \mathrm{OED}_{50}$. The dilution was injected intramuscularly on the thigh of each mouse. In 0.5 or $1 \mathrm{hr}$, each of antitoxins C-AT-2 and P-AT-2 so diluted that an injection dose would contain $0.01-10 \mathrm{U}$ (in anti-lethal unit) was injected intravenously. In 2 days, the injection sites were examined for edema (Table IV).

The longer the period between the toxin and antitoxin injections, the larger the amount of antitoxin necessary to protect the animals against edema. 
TABLE III

Comparison of therapeutic effects of antitoxins as indicated by protection against death Challenge toxin: C-1

\begin{tabular}{|c|c|c|c|c|c|c|c|c|}
\hline \multirow{2}{*}{$\begin{array}{l}\text { Challenge } \\
\text { dose }\end{array}$} & \multirow{2}{*}{ Antitoxin } & \multirow{2}{*}{$\begin{array}{c}\text { Period } \\
(\mathrm{hr})^{2}\end{array}$} & \multicolumn{5}{|c|}{ Amount of antitoxin injected (U/dose) } & \multirow{2}{*}{$\begin{array}{l}\mathrm{ED}_{50} \text { of } \\
\operatorname{AT}^{(\mathbf{U})}\end{array}$} \\
\hline & & & 0 & 0.001 & 0.01 & 0.1 & 1 & \\
\hline \multirow{7}{*}{$\begin{array}{l}5.6 \mathrm{LD}_{50} \\
\text { in } 0.2 \mathrm{ml}\end{array}$} & \multirow{4}{*}{ C-AT-21 } & 1 & $12 / 12^{3}$ & $12 / 12$ & $5 / 12$ & $1 / 12$ & $0 / 12$ & 0.010 \\
\hline & & 2 & $6 / 6$ & $6 / 6$ & $5 / 6$ & $1 / 6$ & $0 / 6$ & 0.032 \\
\hline & & 3 & $6 / 6$ & $6 / 6$ & $4 / 6$ & $1 / 6$ & $0 / 6$ & 0.022 \\
\hline & & & & & & & & $(0.007-0.07)^{4}$ \\
\hline & \multirow{3}{*}{ P-AT-2 1} & 1 & $12 / 12$ & $12 / 12$ & $10 / 12$ & $0 / 12$ & $1 / 12$ & 0,019 \\
\hline & & 2 & $6 / 6$ & $6 / 6$ & $4 / 6$ & $1 / 6$ & $1 / 6$ & 0.031 \\
\hline & & 3 & $6 / 6$ & $6 / 6$ & $4 / 6$ & $4 / 6$ & $1 / 6$ & $\begin{array}{c}0.096 \\
(0.017-0.54)^{4}\end{array}$ \\
\hline
\end{tabular}

1 See "Materials and Methods" for definition.

2 Interval between injections of toxin and antitoxin.

3 Numerator: number of mice died; denominator: number of mice injected.

4 Fiducial limits for $\mathrm{ED}_{50}$ are given in parentheses.

\section{TABLE IV}

Comparison of therapeutic effects of antitoxins as indicated by protection against edema Challenge toxin: C-1

\begin{tabular}{|c|c|c|c|c|c|c|c|c|}
\hline \multirow{2}{*}{$\begin{array}{l}\text { Challenge } \\
\text { dose }\end{array}$} & \multirow{2}{*}{ Antitoxin } & \multirow{2}{*}{$\underset{(\mathrm{Pr})^{2}}{\text { Period }}$} & \multicolumn{5}{|c|}{ Amount of antitoxin injected (U/dose) } & \multirow{2}{*}{$\begin{array}{l}\mathrm{ED}_{50} \text { of } \\
\mathrm{AT}(\mathbf{U})\end{array}$} \\
\hline & & & 0 & 0.01 & 0.1 & 1 & 10 & \\
\hline \multirow{4}{*}{$\begin{array}{l}5.6 \mathrm{OED}_{50} \\
\text { in } 0.2 \mathrm{ml}\end{array}$} & \multirow{2}{*}{$\mathrm{C}-\mathrm{AT}-\mathbf{2}^{1}$} & 0.5 & $8 / 8^{3}$ & $8 / 8$ & $5 / 8$ & $1 / 8$ & $0 / 8$ & 0.118 \\
\hline & & 1 & $8 / 8$ & $8 / 8$ & $7 / 8$ & $4 / 8$ & $2 / 8$ & 1.49 \\
\hline & \multirow{2}{*}{ P-AT-21 } & 0.5 & $8 / 8$ & $8 / 8$ & $8 / 8$ & $1 / 8$ & $0 / 8$ & 0.38 \\
\hline & & 1 & $8 / 8$ & $8 / 8$ & $8 / 8$ & $5 / 8$ & $2 / 8$ & 2. 43 \\
\hline
\end{tabular}

${ }^{1}$ See "Materials and Methods" for the definitions.

2 The interval between injections of toxin and antitoxin.

${ }^{3}$ Numerator: number of edematous mice; denominator: number of mice injected.

In $1 \mathrm{hr}, 0.1 \mathrm{U}$ of either C-AT-2 or P-AT-2 failed to protect them against edema. The two antitoxins were compared for $\mathrm{ED}_{50}$ at different stages; no significant difference was noted between them. They may have had the same protective potencies against edema. From the results of other experiments, 0.1 unit of either antitoxin neutralized in vitro about 5,600 $\mathrm{OED}_{50}$ of $\mathrm{C}-1$.

\section{Discussion}

It has not been clarified whether the lethal and edematizing activities of C. oedematiens culture are elicited by the same molecule. Nevertheless, the potency test of $C$. oedematiens antitoxin is being performed by determining the anti-lethal potency alone in mice. 
C. oedematiens culture contains such biological activities as lethal, edematizing, hemolytic, lecithinase, and permeability-enhancing activities. We demonstrated previously (Izumi et al., 1983) that the same molecule might elicit the lethal and edematizing activities and that the hemolytic and lecithinase activities were separable from these activities.

The present investigation aimed at scrutinizing the relation among such various activities by neutralization tests with crude and partially purified toxins and their antitoxins. The neutralization curves shown in Figs. 1 and 2 and the results given in Table $I$ show that the hyperimmune antitoxins against crude antigen and those against purified one gave the identical anti-lethal and antiedematizing potencies with either crude or purified lethal toxin as test toxin. This indicates that the antibodies participating in neutralization of lethal and edematizing activities of crude and purified toxins are the same. However, unpublished experiments done by us demonstrated that the anti-lethal and anti-edematizing potencies of antitoxins at early stages of immunization were not identical to each other. Such discrepancy can be explained by the different slopes of the neutralization curves. The slope of the neutralization curve of hyperimmune antitoxin was 1.0-1.1; that of antitoxin taken at early stages of immunization was smaller than that, being 0.6-0.8, and the slope with edematizing activity as an indicator was smaller than that with lethal activity as an indicator. The hyperimmune antitoxin is "avid" type and antitoxin taken at early stages of immunization "nonavid" type (Glenny, 1931; Jerne, 1951; Murata, 1966). Since the standard antitoxin used was avid type, an antitoxin of nonavid type would be given a lower potency when titrated at a low level than at a high level. The discrepancy encountered must have been caused by the different avidities.

Immunization of rabbits with highly purified antigen or hemolytic toxin (Table II) indicated that the anti-lethal and anti-edematizing activities are borne by the same molecule and the anti-hemolytic activity by a different molecule.

The therapeutic effects of antitoxin against crude antigen and of that against purified one were the same in respect to protection against both lethal and edematizing activities (Tables III and IV).

From the above results, the lethal and edematizing activities, being particularly important among various biological activities possessed by $C$. oedematiens toxin, are elicited by the same molecule, and the method currently used to titrate $C$. oedematiens antitoxin with anti-lethal potency as an indicator seems justified.

Since the antitoxin obtained by immunizing animals with purified antigen contained neither anti-hemolytic nor anti-lecithinase activity but it was as effective in protection as the antitoxin against crude antigen, the therapeutic effect should depend entirely on the anti-lethal (or anti-edematizing) potency. Purified lethal (or edematizing) toxin can be used, therefore, as the immunogen for manufacture of the antitoxin for therapeutic use. 
Studies with experimental gas gangrene seem necessary to draw a final conclusion on the protective effects of the antitoxin.

\section{ACKnowledgement}

We wish to express our gratitude to Prof. Genji Sakaguchi, College of Agriculture, University of Osaka Prefecture, for his valuable advice and kind help in preparation of the manuscript of this paper. We are grateful also to Dr. Ryosuke Murata, ex-Director General, National Institute of Health, Tokyo, for his helpful advice.

\section{REFERENCES}

Aikat, B. K. ANd Dible, J. H. (1960): The local and general effects of cultures and culturefiltrates of Clostridium oedematiens, Cl. septicum, Cl. sporogenes and Cl. histolyticum. J. Pathol. Bacteriol., 79, 227-241.

Elder, J. M. ANd Miles, A. A. (1957): The action of the lethal toxins of gas-gangrene clostridia on capillary permeability. J. Pathol. Bacteriol., 74, 133-145.

Evans, D. G. (1943): The protective properties of the alpha antitoxin and antihyaluronidase occurring in Cl. welchii type A antiserum. J. Pathol. Bacteriol., 55, 427-434.

Evans, D. G. (1945): The in-vitro production of $\alpha$ toxin, $\theta$ haemolysin and hyaluronidase by strains of $\mathrm{Cl}$. welchii type $\mathrm{A}$, and the relationship of in-vitro properties to virulence for guinea-pigs. J. Pathol. Bacteriol., 57, 75-85.

Ermakova, M. P., Shamraeva, S. A., Zemleyanitskaya, E. P. and Vlasova, E. V. (1971): Morphological and certain histochemical changes caused by Cl. sordellii and oedematiens in cultures of fibroblasts, kidney epithelium and macrophages. Zh. Mikrobiol. Epidemiol. Immunol., 48, 23-28.

GlenNy, A. T. (1931): A system of bacteriology in relation to medicine. VI, p. 150-151. Medical Research Council, London.

Glenny, A. T., Llewellyn-Jones, M. and Mason, J. H. (1931): The intracutaneous method of testing the toxins and antitoxins of the "gas gangrene" organisms. J. Pathol. Bacteriol., 34, 201-211.

Ito, A., Kameyama, S. And Murata, R. (1977): Role of toxins of Clostridium perfringens type $\mathrm{A}$ in the experimental gas gangrene. p.335-340. In J. Bittner, C. Dumitria and $\mathrm{M}$. Zanfirescu [eds.], Proc. Symp. "Actual Data on the Biol. Pathol. Anaero. Bact.", Bucharest. July 24-25, 1975. Medical Publishing House, Bucharest.

IzUmi, N., NiIRo, M. AND Kondo, H. (1983): Clostridium oedematiens type A toxin: The correlation between the lethal and edematizing activities. Japan. J. Med. Sci. Biol., 36, 67-74.

Jerne, N. K. (1951): A study of avidity based on rabbit skin responses to diphtheria toxinantitoxin mixtures. Acta Pathol. Microbiol. Scand., Suppl., 87, 1-183.

Macfarlene, M. G. (1950a): The biochemistry of bacterial toxin. 4. The lecithinase activity of Clostridium haemolyticum toxin. Biochem. J., 47, 267-270.

Macfarlene, M. G. (1950b): The biochemistry of bacterial toxins. 5. Variation in haemolytic activity of immunologically distinct lecithinases towards erythrocytes from different species. Biochem. J., 47, 270-279.

Ministry of Health aND Welfare (1973): Gas-gangrene antitoxin. p. 50-53. In Minimum Requirements for Biological Products. Ministry of Health and Welfare, Tokyo.

Murata, R. (1966): Bioassay of toxin-antitoxin. Media Circle, 81, 1-28 (in Japanese).

OAKley, C. L., Warrack, G. H. ANd Clarke, P. H. (1947): The toxins of Clostridium oedematiens (Cl. novyi). J. Gen. Microbiol., 1, 91-107.

OAKLEY, C. L. AND WARRACK, G. H. (1959): The soluble antigens of Clostridium oedematiens type D (Cl. haemolyticum). J. Pathol. Bacteriol., 78, 543-551.

Rutter, J. M. And Collee, J. G. (1969): Studies on the soluble antigens of Clostridium oedematiens (Cl. novyi). J. Med. Microbiol., 2, 395-417.

Taguchi, R. And Inezawa, H. (1975): Phospholipase C from Clostridium novyi type A. Biochim. Biophys. Acta, 409, 75-85.

Willes, T. (1969): Clostridia of wound infection. p. 167-170. Butterworth and Co. Ltd., London. 